\title{
Influence of exercise and body composition on fasting ghrelin, glucose, insulin and HOMA-IR in men
}

\author{
K. Horner ${ }^{1,2}$, N.M. Byrne ${ }^{1,3}$ and N.A. King ${ }^{1}$ \\ ${ }^{1}$ School of Exercise and Nutrition Sciences, Queensland University of Technology, Brisbane, Australia, \\ ${ }^{2}$ Institute of Food and Health, University College Dublin, Dublin 4, Ireland and ${ }^{3}$ Bond Institute of Health and Sport, \\ Faculty of Health Sciences and Medicine, Bond University, Gold Coast, Australia
}

Ghrelin, glucose and insulin can be influenced by exercise and body composition, and have a role in appetite control. Although, it is well established that a single exercise bout improves glucose metabolism acutely, the effects appear to diminish within 48 to $72 \mathrm{~h}^{(1)}$. The aim of this investigation was to assess the effects of (1) habitual exercise, and (2) a short-term exercise intervention on fasting ghrelin, glucose, insulin and HOMA-IR in men, and to explore associations with body fat and energy expenditure.

In the first cross-sectional study, forty-four men (Active: $n=22$, Inactive: $n=22$; range BMI $21-36 \mathrm{~kg} / \mathrm{m}^{2}$; range percent fat mass 9 $42 \%$ ) were studied. For the second study, a subset of fifteen inactive overweight men subsequently completed a 4-wk supervised exercise intervention, consisting of 5 exercise sessions per week on a cycle ergometer. Body composition was assessed by air displacement plethysmography, activity energy expenditure (AEE) by accelerometery and fasting levels of glucose, insulin and ghrelin were taken. The measurements were repeated $(\geq 48 \mathrm{~h})$ after the final exercise session in the second study.

Active and inactive men differed significantly for a number of characteristics including ghrelin, insulin and HOMA-IR (Table 1a). When the data were pooled $(n=44)$ the strongest correlates of fasting insulin and HOMA-IR were percent fat mass $(\mathrm{r}=0.57$ and $\mathrm{r}=0.56, \mathrm{p}<0.01)$ and resting heart rate $(\mathrm{r}=0.56$ and $\mathrm{r}=0.54, \mathrm{p}<0.01)$ and the strongest correlate of ghrelin was $\operatorname{AEE}(\mathrm{r}=0.33, \mathrm{p}<0 \cdot 05)$.

Following the 4-wk exercise intervention in inactive males, despite a modest reduction in body weight and fat mass and $13 \%$ increase in $\mathrm{VO}_{2} \max$, fasting glucose, insulin and ghrelin were unchanged (Table 1b). Individual variability in response was explained mostly by changes in body fat, with changes in insulin and HOMA-IR from pre-to post-intervention being associated with changes in body fat (insulin: $r=0.69, p<0.01$; HOMA-IR: $r=0.70, p<0.01$ ). Change in glucose was negatively correlated with baseline glucose levels $(r=-0.68, p<0.01)$. Ghrelin did not correlate with changes in other variables or with baseline values.

Table 1a. $n=22$ per group

Table 1b. $n=15$ Pre/Post Intervention

\begin{tabular}{|c|c|c|c|c|c|c|c|c|c|c|}
\hline & \multicolumn{2}{|c|}{ Inactive } & \multicolumn{2}{|c|}{ Active } & \multirow[b]{2}{*}{$P$-value } & \multicolumn{2}{|c|}{ Pre } & \multicolumn{2}{|c|}{ Post } & \multirow[b]{2}{*}{$P$-value } \\
\hline & Mean & $\mathrm{SE}$ & Mean & $\mathrm{SE}$ & & Mean & SE & Mean & $\mathrm{SE}$ & \\
\hline Weight (kg) & $87 \cdot 1$ & $15 \cdot 8$ & $79 \cdot 2$ & 11.7 & 0.07 & $95 \cdot 6$ & $13 \cdot 0$ & $94 \cdot 7$ & $13 \cdot 0$ & $<0.01$ \\
\hline $\operatorname{BMI}\left(\mathrm{kg} / \mathrm{m}^{2}\right)$ & $27 \cdot 4$ & 4.2 & $24 \cdot 5$ & $2 \cdot 6$ & $\mathbf{0 . 0 2}$ & $29 \cdot 7$ & $3 \cdot 3$ & $29 \cdot 3$ & $3 \cdot 2$ & $<0.01$ \\
\hline Body Fat $(\%)$ & $26 \cdot 2$ & $8 \cdot 7$ & $14 \cdot 3$ & $5 \cdot 8$ & $<0.01$ & $30 \cdot 0$ & $6 \cdot 8$ & $29 \cdot 0$ & $6 \cdot 7$ & 0.01 \\
\hline $\mathrm{VO}_{2} \max (\mathrm{ml} / \mathrm{kg} / \mathrm{min})$ & $35 \cdot 3$ & $6 \cdot 5^{1}$ & $46 \cdot 4$ & $8 \cdot 0^{2}$ & $<0.01$ & $34 \cdot 3$ & $5 \cdot 9$ & $38 \cdot 7$ & $5 \cdot 9$ & $<0.01$ \\
\hline Ghrelin (ng/L) & 797 & 341 & 1067 & 308 & $\mathbf{0 . 0 1}$ & 805 & 338 & 761 & 331 & $0 \cdot 12$ \\
\hline Glucose (mmol/L) & $5 \cdot 4$ & $0 \cdot 3$ & $5 \cdot 5$ & 0.5 & $0 \cdot 35$ & $5 \cdot 5$ & $0 \cdot 3$ & $5 \cdot 4$ & $0 \cdot 2$ & $0 \cdot 39$ \\
\hline Insulin $(\mathrm{mU} / \mathrm{L})$ & 8.9 & $4 \cdot 3$ & $4 \cdot 7$ & $2 \cdot 7$ & $<0.01$ & $9 \cdot 4$ & $4 \cdot 7$ & $8 \cdot 7$ & $4 \cdot 2$ & $0 \cdot 19$ \\
\hline HOMA-IR & $2 \cdot 1$ & $1 \cdot 1$ & $1 \cdot 2$ & $0 \cdot 8$ & $<0.01$ & $2 \cdot 3$ & $1 \cdot 2$ & $2 \cdot 1$ & $1 \cdot 1$ & $0 \cdot 20$ \\
\hline
\end{tabular}

$P$-value: Independent t-test (Table 1a), Paired t-test (Table 1b). ${ }^{1} n=19,{ }^{2} n=13$

In conclusion, fasting ghrelin is higher and insulin and HOMA-IR lower in active compared to inactive men. Despite significant improvements in $\mathrm{VO}_{2} \mathrm{max}$, four weeks of exercise training did not alter these measures in inactive overweight men. In the absence of acute exercise effects, these markers may only adapt to a greater volume of exercise or changes in other characteristics associated with regular exercise including reduced fat mass. Findings support the view that exercise should be performed on a regular basis or to induce a greater reduction in fat mass to improve fasting insulin and HOMA-IR. Further work is required to examine implications of these findings for food intake regulation with exercise.

1. Ross R (2003) Diab Care 26, 944-945. 